\title{
Cytomegalovirus Infection of Human Syncytiotrophoblast Cells Strongly Interferes with Expression of Genes Involved in Placental Differentiation and Tissue Integrity
}

\author{
MARK R. SCHLEISS, BRUCE J. ARONOW, AND STUART HANDWERGER \\ Department of Pediatrics [M.R.S.], Division of Infectious Diseases and Immunology, Center for Infectious Diseases and Microbiology \\ Translational Research, University of Minnesota, Minneapolis, Minnesota 55455; Cincinnati Children's Research Foundation \\ [B.J.A., S.H.], Cincinnati, Ohio 45229
}

\begin{abstract}
The principle route of acquisition of cytomegalovirus (CMV) for the fetus is believed to be via the placenta. We subjected purified cytotrophoblast cells obtained from full-term placentas to CMV infection and examined placental gene expression using microarray analyses. Cytotrophoblast cells purified from term placentas differentiated in vitro into a multinucleated syncytium that could be productively infected with CMV, with peak virus titers of approximately $10^{4}$ plaque-forming units $(\mathrm{PFU}) / \mathrm{mL}$ identified in supernatants at late time points postinoculation. Infected syncytiotrophoblast cells expressed CMV-specific transcripts and proteins, as demonstrated by Northern blot and immunofluorescence assays. Microarray analyses revealed that $\mathrm{CMV}$ infection strongly and reproducibly altered trophoblast gene expression, elevating expression of mitotic cell cycle genes, and repressing expression of genes associated with trophoblast differentiation, particularly those associated with formation and stabilization of the extracellular matrix. We conclude that purified, differentiated syncytiotrophoblasts are permissive for CMV replication. Infection of these cells induces significant perturbations in trophoblast transcription. An improved understanding of the molecular events that occur during CMV infection of trophoblasts could provide insights into interventions that might prevent or minimize congenital transmission. (Pediatr Res 61: 565-571, 2007)
\end{abstract}

$\mathrm{B}$ irth defects caused by congenital CMV infection represent a major public health problem. Congenital CMV transmission results in substantial long-term neurodevelopmental morbidity in newborns, including mental retardation and sensorineural hearing loss [reviewed in (1)]. While antiviral therapies may limit severity of SNHL, therapeutic invention has limited ability to reverse other neurologic injuries (2). The most effective strategies for control of congenital CMV may require prevention of fetal infection by preconceptual vaccination or anti-CMV immunoglobulins $(3,4)$. However, vaccines and immunoglobulins are not yet licensed for prevention of congenital CMV infection. Therefore, continued study of the molecular pathophysiology of CMV

Received August 4, 2006; accepted December 19, 2006.

Correspondence: Mark R. Schleiss, M.D., Center for Infectious Diseases and Microbiology Translational Research, University of Minnesota, 2001 6th Street SE, Minneapolis, MN 55455; e-mail: schleiss@umn. edu

Supported by a grant from the March of Dimes Birth Defects Foundation (M.R.S.) and by grants from the National Institutes of Health (HD07447 to S.H. and HD044864 to M.R.S.).

DOI: $10.1203 / p d r .0 b 013 e 318045 b e 6 d$ infection in cell types relevant to congenital transmission is warranted, to help facilitate development of novel disease prevention strategies.

Although there is extensive evidence that CMV-related pathology is caused by direct infection of the fetus in utero, recent work has also highlighted the importance of the role of direct viral infection of the placenta in the pathogenesis of congenital CMV infection $(5,6)$. There is evidence that the route of transmission of CMV to the fetus is via the placenta, which is seeded as a consequence of maternal viremia $(5,6)$. In addition to serving as a gateway to the fetus, the placenta may be directly injured by CMV, conceivably leading to intrauterine growth retardation and fetal disease (7-10). Thus, study of CMV placental infection may facilitate improved understanding of these potentially diverse mechanisms of viral-mediated fetal injury.

A number of reports have identified CMV in placental tissue from clinical samples (11-14). Several in vitro models for studying CMV-placental interactions have also been developed (15-20). Explants of first-trimester placenta onto a matrigel matrix recapitulate in vitro many elements of placental differentiation and invasion, providing a useful system for studying CMV infection of placental cells $(19,20)$. As we show in this report, culture and CMV infection of cytotrophoblast cells purified from term placentas also provides an in vitro model for the study of molecular and cellular events that occur during trophoblast differentiation. These cells aggregate spontaneously and fuse to form a multinucleated syncytium that expresses placental lactogen, human chorionic gonadotropin, and other proteins commonly expressed by differentiated syncytiotrophoblasts, and major genes and functional groups that exhibit dynamic expression changes during differentiation have been identified $(21,22)$. These studies were undertaken to test the hypothesis that CMV infection of these cells would have pathologic effects on trophoblast gene expression in this system that could be identified by microarray analyses.

Abbreviations: CMV, cytomegalovirus; HFF, human foreskin fibroblast; MOI, multiplicity of infection; PFU, plaque-forming unit; SNHL, sensorineural hearing loss 


\section{METHODS}

Viruses and cells. Trophoblast cells were purified from term placentas obtained from women undergoing elective cesarean section, following local institutional review board approval. ELISA (Accurate Scientific, Westbury, NY) confirmed that cord blood was negative for CMV antibodies (data not shown). Cytotrophoblast cells were isolated by enzymatic disaggregation and purified by negative CD9 selection, and cultured as previously described $(21,22)$. The medium was changed at $12 \mathrm{~h}$, when almost all cells were adherent to the bottom of the dish, and then at successive 24-h intervals until the cells exhibited morphologic evidence of syncytia formation (approximately $96 \mathrm{~h}$ after plating).

For CMV inoculations, stocks of the strains AD169, Towne, Davis (the gift of A.P. Geballe), and Toledo (the gift of E.S. Mocarski) were prepared in HFF culture (ATCC number SCRC-1041). Cell-free viral work pools were prepared by sonication and differential centrifugation of tissue culture supernatants after cells had achieved $95-100 \%$ cytopathic effect. Viral stock was prepared using the following methodology. Supernatants were centrifuged in a J2-21 centrifuge at $2500 \mathrm{~g}$ at $25^{\circ} \mathrm{C}$ for $30 \mathrm{~min}$, to pellet cells. This supernatant was transferred to a new centrifuge bottle and centrifuged a second time, again at $2500 \mathrm{~g}$ for $30 \mathrm{~min}$. The supernatant was next transferred to a new centrifuge bottle and centrifuged at $10,000 \mathrm{~g}$ for $90 \mathrm{~min}$ at $4^{\circ} \mathrm{C}$, to pellet virus particles. These were resuspended in DMEM media with $10 \%$ fetal bovine serum (Invitrogen, Carlsbad, CA) prepared in a sucrosephosphate $(0.2 \mathrm{M})$ cryogenic preservation buffer (23). Viral stocks were titered and used to inoculate syncytiotrophoblast cultures at various MOI to assess whether these cells supported viral replication. For microarray experiments, cells were inoculated at a MOI of $5 \mathrm{PFU} /$ cell, using the Toledo strain of CMV. As controls for all experiments, mock-infection was performed using media identical to that used for viral stock preparation (DMEM with $10 \%$ FBS and $0.2 \mathrm{M}$ sucrose-phosphate).

One-step growth curve analyses. CMV stocks of the Toledo strain were used to inoculate syncytiotrophoblast cells and HFF for one-step growth curve analyses. Viruses were used to infect confluent cells at a MOI of $5 \mathrm{PFU} /$ cell. After absorption for $1 \mathrm{~h}$ at $37^{\circ} \mathrm{C}$, the cells were washed with media and a zero time point was harvested. The remainder of the sample was incubated at $37^{\circ} \mathrm{C}$ with additional time points taken at indicated times (Fig. 1). The viral titer of each time point was then determined by plaque titration assay on HFF cells. All assays were done in triplicate, with three replicates obtained for each time point in each experiment. Data represent the mean \pm SD of PFU recovered from each time point.

Immunofluorescence assays. CMV-infected and mock-infected syncytiotrophoblast cells were fixed, permeabilized, and subjected to immunofluorescence using CMV-specific MAb and standard techniques as described elsewhere (24). Cells were incubated with MAb specific for the CMV immediate early protein (IE72) and the structural tegument phosphoprotein, pp65 (UL83), according to the manufacturer's specifications (Argene Inc., North Massapequa, NY). An anti-mouse FITC-conjugated secondary anti-

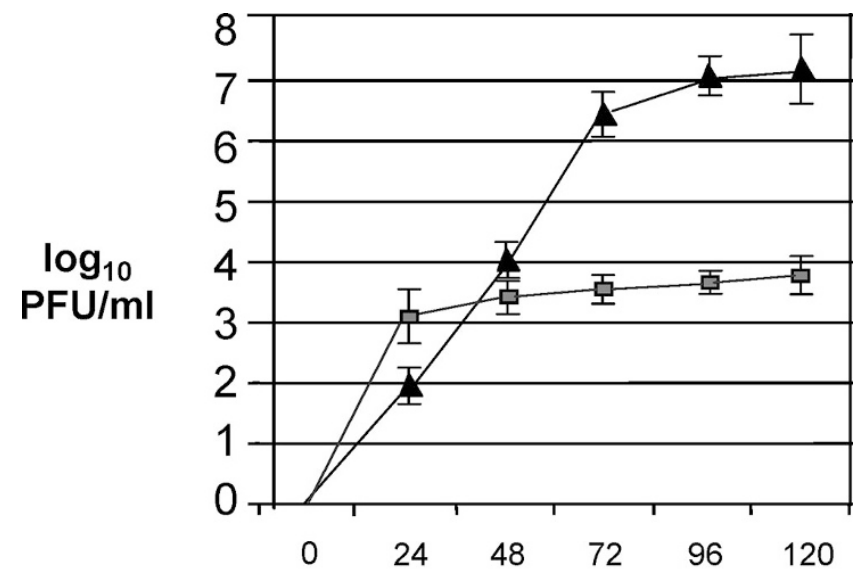

Hours Post-Inoculation

Figure 1. Productive infection of trophoblasts with CMV. Differentiated syncytiotrophoblast cells or HFF were infected with the Toledo strain of CMV at a MOI of 5 PFU/cell. After adsorption of virus, tissue culture supernatants were cultured at the indicated time points to quantify viral recovery. Triangles represent HFF cells, and boxes represent syncytiotrophoblast cells. Data shown are mean $\pm \mathrm{SD}$ of three independent titering experiments. body (Accurate Scientific) was used for visualization by fluorescence microscopy, as previously described (24) (Fig. 2).

RNA purification, Northern blot, and RT-PCR assays. Total RNA was purified from CMV-infected and mock-infected trophoblast cells using the Absolutely RNA purification system (Stratagene, La Jolla, CA), according the manufacturer's specifications. For Northern blot, RNA was subjected to electrophoresis and transfer to Nytran membranes, following by hybridization with ${ }^{32} \mathrm{P}$ dCTP-labeled probes (Fig. $3 A$ ). To further examine transcription profiles in RNA recovered from mock-infected and CMV-infected cells, RT-PCR analyses for syncytin transcript were performed as described elsewhere (25) (Fig. 3B). Briefly, the relative amounts of mRNA for syncytin were determined by semiquantitative RT-PCR using GAPDH mRNA as an internal standard. Total RNA isolated from normal or CMV-infected trophoblast cells was subjected to first-strand cDNA synthesis performed using SuperScript II reverse transcriptase (Invitrogen) and oligo dT according to the manufacturer's protocol. Primer sequences used for detection of syncytin transcripts were $5^{\prime}$ - TCT ATG GAG AAT GCA GCG TCC CG - $3^{\prime}$ and $5^{\prime}$ TAG GCT TAC CAG GCG AGT ATG GG - 3', which resulted in a PCR product of $391 \mathrm{bp}$. Primers for human GAPDH were 5' - CCA TGG AGA AGG CTG GGG - $3^{\prime}$ and $5^{\prime}$ - CAA AGT TGT CAT GGA TGA CC - 3', which resulted in a PCR product of $192 \mathrm{bp}$. The PCR reactions were spiked with $0.1 \mu \mathrm{L}$ of $\left[\gamma^{-}{ }^{32} \mathrm{P}\right] \mathrm{dCTP}(3000 \mathrm{Ci} / \mathrm{mM})$. Optimal PCR cycles required for linear amplification for each set of primers were determined, and amplification in each primer set was kept below saturation levels to permit products to remain within the exponential range. Radiolabeled PCR products were separated by $6 \% \mathrm{PAGE}$ at $225 \mathrm{~V}$ for $3 \mathrm{~h}$. The gel was transferred to $3 \mathrm{M}$ paper, dried, and quantified using a PhosphorImager and ImageQuant 1.2 software (Molecular Dynamics, Sunnyvale, CA).

Microarray analyses. DNA microarray analyses using Affymetrix human U133 GeneChips were performed as previously described $(21,22)$ to compare RNA extracted from control trophoblast cells versus that extracted from cells infected with CMV (Toledo) at a late time point $(96 \mathrm{~h})$ postinfection. RNA was confirmed to have a RNA integrity number of $\geq 7$ before hybridization. Expression data were analyzed using GENESPRING V.6.1 (Silicon Genetics, Redwood City, CA) to select genes that were differentially expressed between the Toledo strain of CMV and the mock-infected controls. Relative gene expression was determined from the Affymetrix cel files by using the Robust Multi-Array Analysis (RMA) algorithm, as developed and described by Irizarry et al. (26). The signal intensity of each of the probe sets was then transformed from a log base 2 to linear values. Each measurement was divided by the median of all measurements in that sample. The samples were normalized to the mean of the control sample(s) hybridized at the same time. Each measurement for each gene in those specific samples was divided by the median of that gene's measurements in the corresponding control samples. We analyzed the control versus CMV groups using a 2-fold expression level filter and Welch's approximate $t$ test with multiple testing correction algorithm (Welch's approximate $t$ test with Benjamini and Hochberg multiple testing correction algorithm; see Fig. 4).
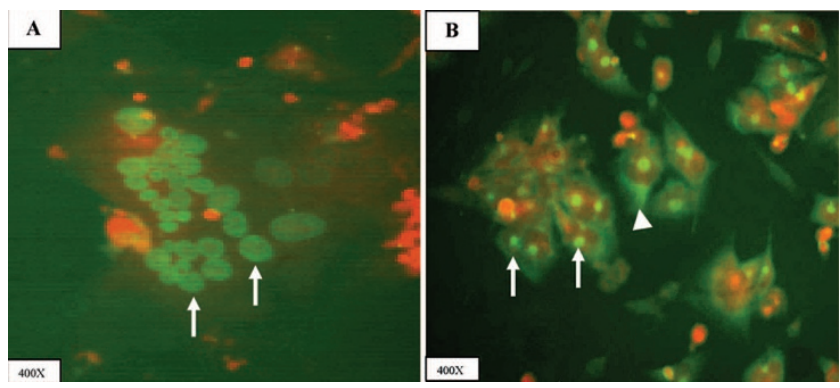

Figure 2. Immunofluorescence analysis of CMV-infected trophoblast cells. Differentiated syncytiotrophoblast cells were infected with the Toledo strain of CMV. After infection, cells were incubated with an anti-CMV IE1 (IE72) MAb (A), or an anti-CMV pp65 (UL83) antibody (B). Cells were next incubated with a FITC-conjugated anti-mouse secondary antibody, and then visualized by fluorescence microscopy. The IE72 antibody exhibited the anticipated nuclear pattern of fluorescence (A, arrows) whereas the pp65 antibody $(B)$ exhibited both nuclear (arrow) and cytoplasmic (arrowhead) patterns of fluorescence. No background fluorescence was observed using these antibodies with mock-infected cells (data not shown). Scale bar indicating degree of magnification is indicated. 
A

GADPH

TRL4 (HCMV)

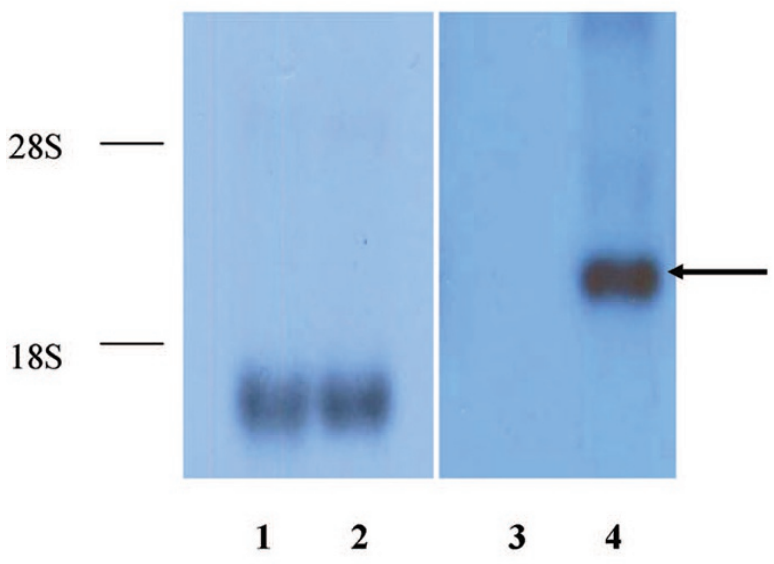

B

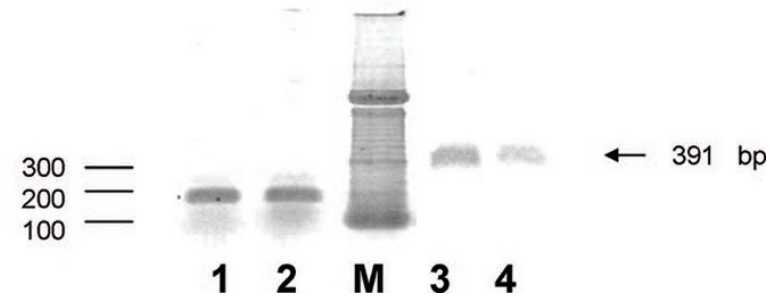

Figure 3. Transcription from CMV-infected and control trophoblast cells. (A) Northern blot analysis of RNA purified from mock-infected (lanes 1,3) or CMV-infected (lanes 2, 4) trophoblast cells probed either with a GAPDH probe (left blot) or a probe for the CMV TRL4 transcript (right blot). (B) Quantitative reverse-transcriptase PCR for GAPDH mRNA (left panel) and syncytin RNA (right panel) in mock-infected and CMV-infected trophoblast cells. Quantitative analysis (normalized to GAPDH expression, lanes 1 and 2) of the 391-bp syncytin product (arrow) indicates a reduction in syncytin expression levels of approximately 25\% in CMV-infected cells (lane 4), compared with mock-infected control (lane 3). Results shown are representative of 3 independent experiments.

\section{RESULTS}

Syncytiotrophoblast cells support productive CMV infection in vitro. Cytotrophoblast cells were plated and allowed to differentiate into syncytiotrophoblast cells, as previously described $(21,22)$. Replication kinetics were determined for the Toledo strain in syncytiotrophoblast cells (Fig. 1) and compared with replication in HFF. Tissue culture media from syncytiotrophoblast cells was found to contain on average a peak level of approximately $4 \log _{10} \mathrm{pfu} / \mathrm{mL}$ in the supernatant at late time points following viral inoculation (Fig. 1).

The permissiveness of syncytiotrophoblast for CMV replication was further explored using immunofluorescence assay (Fig. 2). These assays used MAb that targeted IE72 protein, and a CMV structural protein, pp65 (ppUL83) (27). CMVinfected syncytiotrophoblasts expressed both proteins abundantly (Fig. 2). The localization of these proteins in infected syncytiotrophoblast cells was similar to that described in other CMV-permissive cells, with the IE72 protein localized exclusively in the nuclei of infected cells. In contrast, the pp65 protein localized to both nuclei and cytoplasm of infected cells (Fig. 2B, arrows and arrowheads).
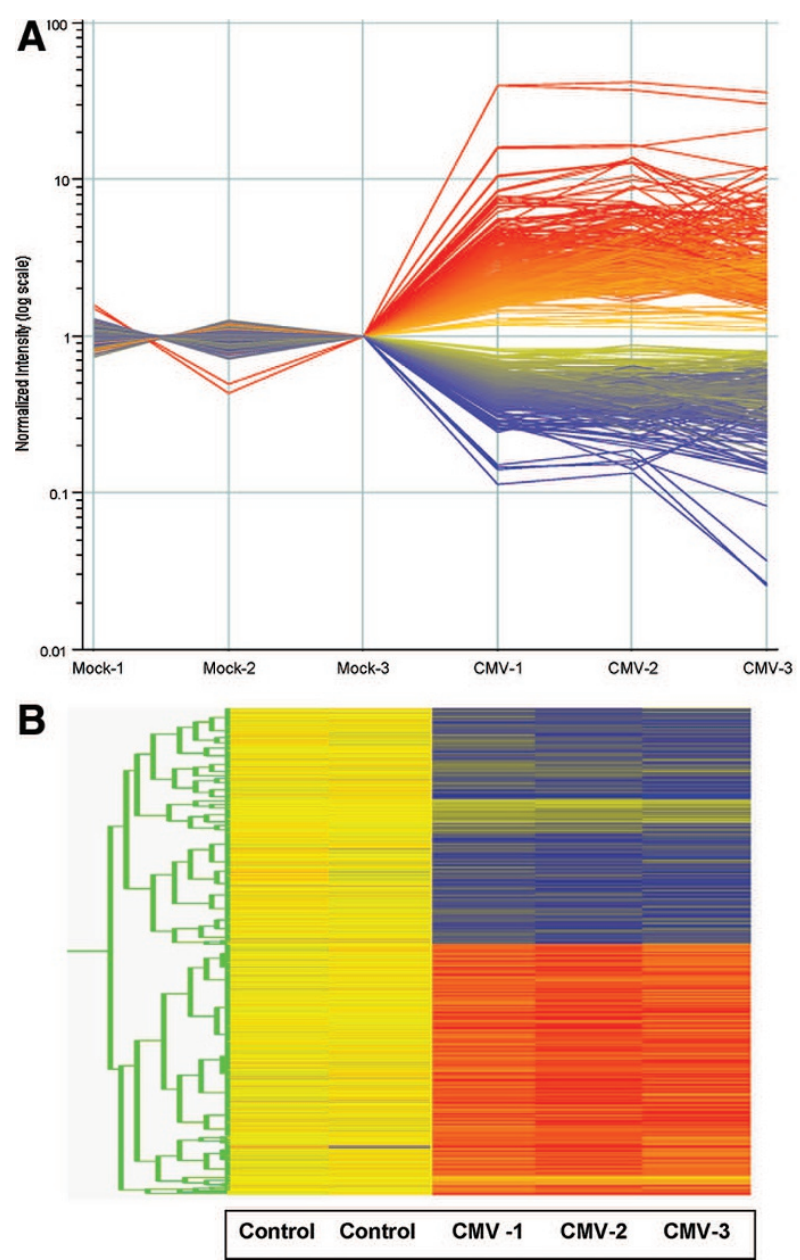

Figure 4. Impact of HCMV infection on trophoblast cell gene expression. To examine perturbations in trophoblast cell gene expression induced by CMV infection, DNA microarray analyses using Affymetrix human U133 GeneChips were performed, comparing RNA extracted from control trophoblast cells $v s$ that extracted from cells infected with the Toledo strain of CMV at a late time point ( $96 \mathrm{~h}$ ) postinfection. (A) Expression data were analyzed using GENESPRING V.6.1 (Silicon Genetics) to select genes that were differentially expressed between the Toledo strain of CMV and the negative (mockinfected) trophoblast cell culture controls. Five hundred forty-four genes were identified with averaged expression intensity in CMV-infected samples higher or lower than the averaged expression intensity in the control samples by at least 2-fold, and expression in CMV-infected samples deviated from that of control samples with a significance cut-off of $p<0.05$ (Welch's approximate $t$ test with Benjamini and Hochberg multiple testing correction algorithm). (B) Profiles of normalized mock-infected trophoblast cells (yellow, control) and three independent experiments using RNA from CMV-infected trophoblast cells (CMV 1-3). The most down-regulated (blue) gene families are indicated in greater detail in Table 1, and the most up-regulated (red) are indicated in Table 2 .

Transcriptional analyses of CMV-infected and control trophoblast cells. To examine the impact of CMV infection on transcription in cultured syncytiotrophoblast cells, RNA was purified from CMV-infected and mock-infected cells at $96 \mathrm{~h}$ postinfection. Northern blot analysis was then performed using a probe for the major early CMV transcript, $2.7 \beta$ (UL4) (28). This transcript was abundantly expressed in CMVinfected, but not mock-infected, trophoblast cells (Fig. 3B). To further compare transcription from mock-infected and infected cells, reverse-transcriptase PCR (RT-PCR) was per- 
Table 1. Trophoblast genes identified as down-regulated by cytomegalovirus infection

\begin{tabular}{|c|c|c|}
\hline Down-regulated trophoblast gene & $\begin{array}{l}\text { Accession } \\
\text { number }\end{array}$ & $\begin{array}{c}\text { Fold } \\
\text { decrease }\end{array}$ \\
\hline \multicolumn{3}{|l|}{ Cell and tissue structural dynamics } \\
\hline Matrix metalloproteinase 3 preproprotein & NM_002422 & 13.6 \\
\hline Cadherin 11 , type 2 preproprotein & NM_001797 & 9.8 \\
\hline Junctional adhesion molecule 2 precursor & NM_021219 & 4.8 \\
\hline Laminin, alpha 4 precursor & NM_002290 & 4.7 \\
\hline Fibulin 1 isoform $\mathrm{C}$ precursor & NM_006487 & 3.1 \\
\hline $\begin{array}{l}\text { UDP-N-acetylglucosamine-2-epimerase/ } \\
\text { N-acetylmannosamine kinase }\end{array}$ & NM_005476 & 3.0 \\
\hline Integrin beta chain, beta 3 precursor & NM_000212 & 2.6 \\
\hline Mannosidase, alpha, class $1 \mathrm{~A}$, member 1 & NM_005907 & 2.4 \\
\hline Fibrillin 1 & NM_000138 & 2.3 \\
\hline \multicolumn{3}{|l|}{ Cell cycle and apoptosis } \\
\hline Cyclin-dependent kinase inhibitor $1 \mathrm{C}$ & NM_000076 & 3.6 \\
\hline PAR-6 beta & NM_032521 & 2.5 \\
\hline Epidermal growth factor receptor & AK_026818 & 2.2 \\
\hline \multicolumn{3}{|l|}{ Intracellular communication } \\
\hline Junctional adhesion molecule 2 precursor & NM_021219 & 4.8 \\
\hline Stanniocalcin 1 & NM_002195 & 3.1 \\
\hline Endothelial PAS domain protein 1 & NM_006113 & 2.3 \\
\hline Epidermal growth factor receptor & NM_021005 & 2.2 \\
\hline Semaphorin $5 \mathrm{~A}$ & NM_013402 & 2.1 \\
\hline \multicolumn{3}{|l|}{ Metabolism } \\
\hline Fatty acid desaturase 1 & NM_013402 & 2.1 \\
\hline \multicolumn{3}{|l|}{ Regulation of gene expression } \\
\hline $\begin{array}{l}\text { Ras protein-specific guanine } \\
\text { nucleotide-releasing factor } 2\end{array}$ & NM_006909 & 3.2 \\
\hline Phospholipase C-like 2 & NM_015184 & 3.2 \\
\hline Par-6 partitioning defective 6 homolog beta & NM_032521 & 2.5 \\
\hline Transcription factor AP-2 alpha & NM_001032280 & 2.5 \\
\hline GATA binding protein 3 & NM_001002295 & 2.4 \\
\hline Zinc finger homeobox $1 \mathrm{~b}$ & NM_014795 & 2.4 \\
\hline Nuclear receptor coactivator 3 & NM_006534 & 2.4 \\
\hline Vav 3 oncogene & NM_006113 & 2.3 \\
\hline $\begin{array}{l}\text { Nuclear receptor subfamily } 2 \text {, } \\
\text { group F, member } 2\end{array}$ & NM_003966 & 2.1 \\
\hline
\end{tabular}

Total fold-change in genes is indicated in rank order, with GenBank accession number.

formed for the "housekeeping" gene, GAPDH, and the syncytin gene, which is abundantly expressed in trophoblast cells $(25,29)$. These analyses indicated that CMV infection resulted in a $25 \%$ decrease in syncytin mRNA, normalized against expression of GAPDH (Fig. $3 B$ ).

Microarray analyses of RNA from CMV-infected and control trophoblasts reveal altered transcription patterns following infection. Microarrays were performed with RNA purified from mock-infected and CMV-infected syncytiotrophoblasts as described in "Methods." Microarrays were compared by analysis of the control versus CMV groups. Data were analyzed from multiple, independently conducted infection experiments (a total of six experiments: three with mockinfected cells and three with CMV-infected cells). We used Welch's approximate $t$ test with Benjamini and Hochberg multiple testing correction algorithm and top-ranked differential expression criteria of RMA-normalized expression data (26). This resulted in the identification of 544 genes whose expression differed by more than 2-fold in CMV samples relative to the control sample, with a significance cut-off of
Table 2. Trophoblast genes identified as up-regulated by cytomegalovirus infection

\begin{tabular}{|c|c|c|}
\hline Up-regulated trophoblast gene & $\begin{array}{l}\text { Accession } \\
\text { number }\end{array}$ & $\begin{array}{l}\text { Fold } \\
\text { increase }\end{array}$ \\
\hline \multicolumn{3}{|l|}{ Cell and tissue structural dynamics } \\
\hline $\begin{array}{l}\text { Fibronectin leucine-rich transmembrane } \\
\text { protein } 3\end{array}$ & NM_013281 & 4.5 \\
\hline Cadherin 3 type 1 , P-cadherin & NM_001793 & 3.8 \\
\hline Tetrespanin 2 & NM_005725 & 3.1 \\
\hline Laminin, alpha 3 & NM_000227 & 2.5 \\
\hline \multicolumn{3}{|l|}{ Cell cycle and apoptosis } \\
\hline TTK protein kinase & NM_003318 & 5.2 \\
\hline Cell division cycle $25 \mathrm{~A}$ & NM_001789 & 4.3 \\
\hline DNA replication factor & NM_030928 & 2.8 \\
\hline $\mathrm{CDC} 28$ protein kinase regulatory subunit 2 & NM_001827 & 2.6 \\
\hline RAD51 homolog & NM_002875 & 2.6 \\
\hline Stratifin & NM_006142 & 2.5 \\
\hline Transforming growth factor, alpha & NM_003236 & 2.4 \\
\hline \multicolumn{3}{|l|}{ Intracellular communication } \\
\hline RAP1A, member of RAS oncogene family & NM_002824 & 44.8 \\
\hline Neuromedin U & NM_006681 & 14.5 \\
\hline Tachykinin, precursor 1 & NM_003182 & 7.2 \\
\hline Natriuretic peptide precursor B & NM_002521 & 6.3 \\
\hline Glycine receptor, beta & NM_000824 & 5.8 \\
\hline Adrenergic, beta-2, receptor & NM_000024 & 5.8 \\
\hline Relaxin 2 & NM_005059 & 5.0 \\
\hline Cholecystokinin & NM_000729 & 4.5 \\
\hline $\begin{array}{l}\text { Fibronectin leucine rich transmembrane } \\
\text { protein } 3\end{array}$ & NM_013281 & 4.5 \\
\hline \multicolumn{3}{|l|}{ Regulation of gene expression } \\
\hline Zinc finger protein 85 (HPF4, HTF1) & NM_003429 & 4.7 \\
\hline Single-stranded DNA binding protein 2 & NM_012446 & 3.5 \\
\hline Hairy and enhancer of split 4 & NM_021170 & 3.5 \\
\hline Forkhead box Q1 & NM_033260 & 3.2 \\
\hline Myelin expression factor 2 & NM_016132 & 2.8 \\
\hline Homeobox A1 & NM_005522 & 2.8 \\
\hline
\end{tabular}

Total fold-change is indicated in rank order, along with the GenBank accession number.

$p<0.05$ (Welch's approximate $t$ test with Benjamini and Hochberg multiple testing correction algorithm). Using a gene ontology analysis tool, DAVID 2.0 (30), we found that CMV infection strongly and reproducibly altered multiple trophoblast cell gene expression profiles. These effects are summarized in Tables 1 and 2. This analysis identified five gene families exhibiting noteworthy changes in the pattern of transcription: 1) cell and tissue structural dynamics; 2) cell cycle and apoptosis genes (in particular, elevation of the expression of mitotic cell cycle genes); 3) genes involved in intracellular communication; 4) metabolism genes; and 5) genes involved in regulation of gene expression (Fig. 4; Tables 1 and 2). Genes involved in the formation and stabilization of the extracellular matrix were significantly dysregulated, including matrix metalloproteinase 3 (13.6-fold down-regulation), cadherin (9.8-fold down-regulation), and laminin alpha-4 precursor (4.7-fold down-regulation). Other dysregulated genes included several in the intracellular communication gene family, including RAP1A, a member of the RAS oncogene family (up-regulated 44.8-fold), neuromedin (up-regulated 14.5fold), and tachykinin (up-regulated 7.2-fold). It was of particular interest to note that transcription factor AP2 alpha was 
decreased (2.5-fold down-regulation), inasmuch as previous studies identified a critical role for this gene in placental expression of lactogen, gonadotropin, and other genes involved in placental homeostasis $(25,29$; Table 1$)$.

\section{DISCUSSION}

These studies of the impact of CMV infection on placental gene expression were undertaken to explore, using microarray analyses, potential modifications in trophoblast transcription, toward a long-term goal of understanding placental mechanisms of congenital virus transmission. Previous study of purified cytotrophoblast cells obtained from term placentas had identified genetic programs and pathways that underlie differentiation into syncytiotrophoblast cells (31). Thus, it was of interest to determine the permissivity of these cells for infection with CMV. We observed that these differentiated syncytiotrophoblast cells were fully permissive for CMV replication in our study, albeit at reduced levels compared with fibroblast cells (Fig. 1). It was of interest to compare these results to those described by other investigators who have explored CMV infection of placenta in cell and tissue culture models. Previous work with term placentas demonstrated the permissivity of purified trophoblasts for CMV infection, using the laboratory-adapted strain, AD169 (15). Syncytiotrophoblast infection was demonstrated in vivo in a study of thirdtrimester placenta, using in situ hybridization and PCR techniques (11). Another study of purified syncytiotrophoblast cultures demonstrated that these cells could be permissively infected with a number of laboratory-adapted strains of CMV, as with clinical isolates, although infection efficiencies differed amongst different strains (18). Similar to our observations, viral titers in tissue culture supernatant were relatively low in this study, presumably reflecting the cell-associated nature of CMV infection. Although our studies attest to the permissiveness of syncytiotrophoblast for productive infection, infection of these cells with CMV has not been as straightforward in the hands of other investigators. For example, in studies of first trimester placental explants, maintained either in primary tissue culture or following culture on a matrigel matrix, syncytiotrophoblasts are only rarely infected $(17,19)$. Other regions, including the decidual basalis, have appeared to be more permissive for viral infection in studies of biopsies of primary tissue samples (32). Divergent findings from these various studies may be a result of different culturing procedures, or differences in the gestational age of placental tissue (6). Differences in expression of CMV receptors between syncytiotrophoblasts and cytotrophoblasts have also been proposed (16), and this factor could explain the variation in the permissiveness of placental cells for CMV infection described in previous reports.

We focused on term trophoblasts in this study, because of their availability, and because of the body of previously acquired data that carefully defined, by microarray analyses, the transcriptional profile of these cells (18). Our results confirm those of other investigators (18) regarding the permissivity of these cells for CMV infection in vitro. The Toledo strain of CMV was used for our microarray analyses because of the fact that the Toledo genome is more similar to that of wild-type strains of CMV than other laboratory-adapted strains (33), and because the Toledo strain has been found to retain tropism for a wide range of cell types in other in vitro models (34). Future studies of primary clinical isolates of CMV would potentially be of significant translational interest in this model.

As noted, previous studies using microarrays had defined the normal transcriptional events that occur during the process of cytotrophoblast cell differentiation into syncytiotrophoblast cells in vitro, in the absence of CMV $(21,22,31)$. In the present study, infection of syncytiotrophoblast cells with CMV resulted in modification of this previously defined program in several gene categories. Table 1 shows the most highly modified genes in each of the categories, along with the percent change in mRNA abundance from that of control, mockinfected cells cultured in the identical manner, except for infection with CMV. These analyses identified 544 genes with significant up- or down-regulation induced by CMV infection. Of note, CMV infection strongly and reproducibly altered trophoblast expression of mitotic cell cycle genes, and strongly repressed the expression of genes associated with trophoblast differentiation, particularly those associated with formation and stabilization of the extracellular matrix (Tables 1, 2; Fig. 4). It was of considerable interest that genes involved in the formation and stabilization of the extracellular matrix were significantly dysregulated, including matrix metalloproteinase 3 (13.6-fold down-regulation), cadherin (9.8-fold down-regulation), and laminin alpha-4 precursor (4.7-fold down-regulation). Down-regulation of the genes in the cell and tissue structural dynamics category may result in changes in the composition and function of the extracellular matrix of CMV-infected cells, an effect which in turn may impact the transmission of CMV to the fetus.

Other significantly dysregulated genes included several in the intracellular communication gene family, including RAP1A, a member of the RAS oncogene family (up-regulated 44.8-fold), neuromedin (up-regulated 14.5-fold), and tachykinin (up-regulated 7.2-fold). Transcription factor AP-2 alpha was also decreased, with a 2.5-fold down-regulation. Since AP-2 alpha has been shown to be critical for the expression of placental lactogen, chorionic gonadotropin, and many other proteins expressed by terminally differentiated syncytiotrophoblast cells, it is plausible that repression of AP-2 mRNA levels could impair the expression of these proteins in the infected cells and could result in decreased hormone production and alteration in other cellular functions $(25,29)$, which in turn could have deleterious effects on placental development. Another dysregulated mRNA of interest within the family of genes involved in regulation of gene expression family was GATA binding protein 3 (Table 1; 2.4-fold decrease). Conceivably, decreased expression of this transcription factor could have an impact on placental structure, via downregulation of syncytin expression $(21,22)$. Consistent with this prediction, we observed a $25 \%$ decrease in syncytin expression, by RT-PCR, in RNA purified from CMV-infected trophoblast cells, compared with mock-infected cells (Fig. 3B). 
Microarray analysis has been performed by other investigators to explore the effect of CMV infection on transcription in a variety of cell types, although it has not been previously described for CMV-infected trophoblasts. In a study of CMVinfected fibroblasts using an Affymetrix array containing 6,600 human mRNA, 258 mRNA were identified that changed by a factor of 4 or more within the first $24 \mathrm{~h}$ of viral infection (35). Another study of the impact of CMV on infected fibroblasts identified genes involved in transcriptional regulation, oncogenesis, cell cycle regulation, immune system regulation, signal transduction, and cell adhesion, as being significantly modified by CMV infection (36). Because of the importance of the placenta as a target for CMV infection before fetal transmission in utero, we chose to study syncytiotrophoblast cells, with the long-term goal of an improved understanding of viral factors that might be important in promoting congenital transmission. Our findings, although preliminary, provide support for further experimental evaluation of a hypothesis of fetal injury induced by CMV that is not necessarily due to the direct infection of fetal cells per se, but could be induced by $\mathrm{CMV}$-mediated perturbations in placental structure and function that, in turn, could lead to fetal damage via placental insufficiency. The finding that CMV infection markedly perturbs expression of genes required for normal trophoblast differentiation is compatible with a model whereby viral infection leads to placental insufficiency and attendant fetal compromise through modification of expression of genes involved in structural integrity and differentiation. Future microarray-based analyses of recombinant CMVs, deleted in regulatory and immunomodulatory genes, could facilitate testing of hypotheses about the putative viral factor(s) responsible for mediating these effects, which in turn could have translational implications for the rational design of live, attenuated vaccines with optimal safety profiles for future clinical trials. In addition to future studies of clinical isolates of CMV on trophoblast transcription, additional studies are required of multiple time points postinfection, to better define kinetic classes of CMV genes involved in mediating these effects. Recent evidence suggests that the salutary effect of anti-CMV immmune globulin in pregnant women with primary CMV infection is mediated through preservation of placental structure and function (37). Since optimizing the integrity and health of the placenta may be the key to preventing adverse fetal outcomes in the setting of maternal CMV infections (38), further study of the impact of CMV infection on placental gene expression may provide insights into novel therapeutic and preventative strategies for this important public health problem.

\section{CONCLUSION}

Syncytiotrophoblast cells purified from term placentas are fully permissive for CMV infection and inoculation of these cells results in a productive infection in which infectious virus is present in tissue culture supernatants. CMV-infected trophoblasts have dramatically altered patterns of transcription, compared with mock-infected cells. Microarray analyses indicate that CMV infection strongly and reproducibly alters trophoblast expression of mitotic cell cycle genes, and strongly repressing the expression of genes associated with trophoblast differentiation, particularly those associated with formation and stabilization of the extracellular matrix. Whether these perturbations of trophoblast gene expression diminish integrity of the placental barrier at the cellular level, or modify CMV transmission to the fetus, requires further experimental analysis.

Acknowledgments. The authors thank Greg Stroup and Mike Hubert for technical assistance. We also thank A.P. Geballe (Fred Hutchinson Cancer Research Center) and E.S. Mocarski (Emory University) for the gift of CMV isolates.

\section{REFERENCES}

1. Griffiths PD, Walter S 2005 Cytomegalovirus. Curr Opin Infect Dis;18:241-245

2. Schleiss MR, McVoy M 2004 Overview of congenitally and perinatally acquired cytomegalovirus infections: recent advances in antiviral therapy. Expert Rev Anti Infect Ther 2:389-403

3. Schleiss MR, Heineman TC 2005 Progress toward an elusive goal: current status of cytomegalovirus vaccines. Expert Rev Vaccines 4:381-406

4. Nigro G, Adler SP, La Torre R, Best AM 2005 Congenital cytomegalovirus collaborating group. Passive immunization during pregnancy for congenital cytomegalovirus infection. N Engl J Med 353:1350-1362

5. Koi H, Zhang J, Parry S 2001 The mechanisms of placental viral infection. Ann N Y Acad Sci 943:148-156

6. Pereira L, Maidji E, McDonagh S, Tabata T 2005 Insights into viral transmission at the uterine-placental interface. Trends Microbiol 13:164-174

7. Garcia AG 1982 Placental morphology of low-birth-weight infants born at term. Contrib Gynecol Obstet 9:100-112

8. Salafia CM, Minior VK, Pezzullo JC, Popek EJ, Rosenkrantz TS, Vintzileos AM 1995 Intrauterine growth restriction in infants of less than thirty-two weeks' gestation: associated placental pathologic features. Am J Obstet Gynecol 173:1049_ 1057

9. Fox H 1993 The placenta and infection. In: Redman CW, Sargent I, Starkey PM (eds) The Human Placenta. Blackwell Scientific, Oxford, pp 313-333

10. Bernstein PS, Divon MY 1997 Etiologies of fetal growth restriction. Clin Obstet Gyencol 40:723-729

11. Trincado DE, Munro SC, Camaris C, Rawlinson WD 2005 Highly sensitive detection and localization of maternally acquired human cytomegalovirus in placental tissue by in situ polymerase chain reaction. J Infect Dis 192:650-657

12. Muhlemann K, Menegus MA, Miller RK 1995 Cytomegalovirus in the perfused human term placenta in vitro. Placenta 16:367-373

13. McDonagh S, Maidji E, Chang HT, Pereira L 2006 Patterns of human cytomegalovirus infection in term placentas: a preliminary analysis. J Clin Virol 35:210215

14. Sinzger C, Muntefering H, Loning T, Stoss H, Plachter B, Jahn G 1993 Cell types infected in human cytomegalovirus placentitis identified by immunohistochemical double staining. Virchows Arch A Pathol Anat Histopathol 423:249-256

15. Halwachs-Baumann G, Wilders-Truschnig M, Desoye G, Hahn T, Kiesel L, Klingel K, Rieger P, Jahn G, Sinzger C 1998 Human trophoblast cells are permissive to the complete replicative cycle of human cytomegalovirus. J Virol 72:7598-7602

16. Hemmings DG, Guilbert LJ 2002 Polarized release of human cytomegalovirus from placental trophoblasts. J Virol 76:6710-6717

17. Gabrielli L, Losi L, Varani S, Lazzarotto T, Eusebi V, Landini MP 2001 Complete replication of human cytomegalovirus in explants of first trimester human placenta. J Med Virol 64:499-504

18. Hemmings DG, Kilani R, Nykiforuk C, Preiksaitis J, Guilbert LJ 1998 Permissive cytomegalovirus infection of primary villous term and first trimester trophoblasts. J Virol 72:4970-4979

19. Fisher S, Genbacev O, Maidji E, Pereira L 2000 Human cytomegalovirus infection of placental cytotrophoblasts in vitro and in utero: implications for transmission and pathogenesis. J Virol 74:6808-6820

20. Yamamoto-Tabata T, McDonagh S, Chang HT, Fisher S, Pereira L 2004 Human cytomegalovirus interleukin-10 downregulates metalloproteinase activity and impairs endothelial cell migration and placental cytotrophoblast invasiveness in vitro. J Virol 78:2831-2840

21. Aronow BJ, Richardson BD, Handwerger S 2001 Microarray analysis of trophoblast differentiation: gene expression reprogramming in key gene function categories. Physiol Genomics 6:105-116

22. Handwerger S, Aronow B 2003 Dynamic changes in gene expression during human trophoblast differentiation. Recent Prog Horm Res 58:263-281

23. Howell CL, Miller MJ 1983 Effect of sucrose phosphate and sorbitol on infectivity of enveloped viruses during storage. J Clin Microbiol 18:658-662

24. McGregor A, Liu F, Schleiss MR 2004 Molecular, biological, and in vivo characterization of the guinea pig cytomegalovirus (CMV) homologs of the human CMV matrix proteins pp71 (UL82) and pp65 (UL83). J Virol 78:9872-9889 
25. Cheng YH, Handwerger S 2005 A placenta-specific enhancer of the human syncytin gene. Biol Reprod 73:500-509

26. Irizarry RA, Bolstad BM, Collin F, Cope LM, Hobbs B, Speed TP 2003 Summaries of Affymetrix GeneChip probe level data. Nucleic Acids Res 31:e15

27. Boeckh M, Boivin G 1998 Quantitation of cytomegalovirus: methodologic aspects and clinical applications. Clin Microbiol Rev 11:533-554

28. Geballe AP, Spaete RR, Mocarski ES 1986 A cis-acting element within the 5' leader of a cytomegalovirus beta transcript determines kinetic class. Cell 46:865-867

29. Cheng YH, Aronow BJ, Hossain S, Trapnell B, Kong S, Handwerger S 2004 Critical role for transcription factor AP-2 alpha in human trophoblast differentiation. Physiol Genomics 18:99-107

30. Dennis G, Jr. Sherman BT, Hosack DA, Yang J, Gao W, Lane HC, Lempicki RA 2003 DAVID: Database for annotation, visualization, and integrated discovery. Genome Biol 4:P3

31. Kong S, Aronow BJ, Handwerger S 2006 Gene expression microarray data analysis of decidual and placental cell differentiation. Methods Mol Med 121: $425-438$

32. McDonagh S, Maidji E, Ma W, Chang HT, Fisher S, Pereira L 2004 Viral and bacterial pathogens at the maternal-fetal interface. J Infect Dis 190:826-834
33. Prichard MN, Penfold ME, Duke GM, Spaete RR, Kemble GW 2001 A review of genetic differences between limited and extensively passaged human cytomegalovirus strains. Rev Med Virol 11:191-200

34. MacCormac LP, Grundy JE 1999 Two clinical isolates and the Toledo strain of cytomegalovirus contain endothelial cell tropic variants that are not present in the AD169, Towne, or Davis strains. J Med Virol 57:298-307

35. Zhu H, Cong JP, Mamtora G, Gingeras T, Shenk T 1998 Cellular gene expression altered by human cytomegalovirus: global monitoring with oligonucleotide arrays. Proc Natl Acad Sci U S A 95:14470-14475

36. Challacombe JF, Rechtsteiner A, Gottardo R, Rocha LM, Browne EP, Shenk T, Altherr MR, Brettin TS 2004 Evaluation of the host transcriptional response to human cytomegalovirus infection. Physiol Genomics 18:51-62

37. La Torre R, Nigro G, Mazzocco M, Best AM, Adler SP 2006 Placental enlargement in women with primary maternal cytomegalovirus infection is associated with fetal and neonatal disease. Clin Infect Dis 43:994-1000

38. Schleiss MR 2006 The role of the placenta in the pathogenisis of congenital cytomegalovirus infection: is the benefit of cytomegalovirus immune globulin for the newborn mediated through the improved placental health and function? Clin Infect Dis 43:1001-1003 